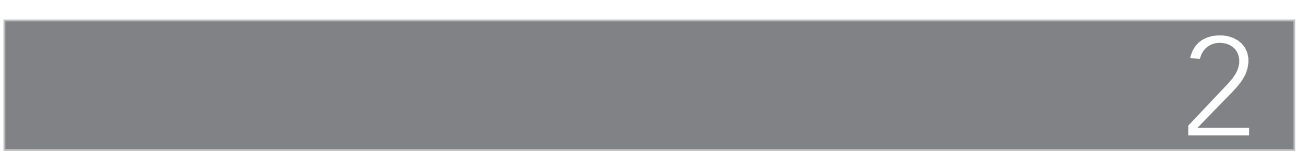

\title{
Analyzing Economic Outcomes in Advanced Practice Nursing
}

\author{
LAURA E. STARBIRD | KEVIN D. FRICK | CATHERINE C. COHEN | \\ PATRICIA W. STONE
}

\section{CHAPTER OBJECTIVES}

1. Present an overview of five different types of economic evaluations that an APRN may encounter.

2. Outline appropriate outcome measures for each type of analysis.

3. Summarize and critique published examples of each type of economic evaluation.

4. Contrast economic evaluation methodology with that of comparative-effectiveness studies and business case studies.

5. Discuss methodological issues of importance to economic evaluations.

\section{CHAPTER DISCUSSION QUESTIONS}

1. How does comparative-effectiveness research compare with cost-effectiveness research and business case studies?

2. In what scenario would a cost-utility methodology be appropriate? Provide an example.

3. If studying three interventions with no single standard outcome measure (or validated means of clinical outcome aggregation), which methodology may be most appropriate?

4. What is a key assumption required for a successful cost-benefit analysis (CBA)? How are the outcomes of CBAs presented?

5. Use a "two-step" approach to determine cost of a new antibiotic formulation that requires 4 minutes of reconstitution preparation by the $\mathrm{RN}$ immediately prior to intravenous infusion.

\section{INTRODUCTION}

Cost-effectiveness of healthcare practice is an increasingly important consideration in the delivery of care and consequently in nursing research. The growing proportion of older adults in the U.S. population, improvements in healthcare technology, direct-to-consumer advertising for pharmaceuticals, increasing costs of doing business in other sectors besides healthcare, and international competitive pressures on wages and benefits have drawn greater attention to the costs of healthcare over time. U.S. healthcare spending in 2018 
grew $4.6 \%$, which was more than double the rate of inflation and accounted for $17.7 \%$ of gross domestic product (Centers for Medicare \& Medicaid Services, 2020; Hartman et al., 2019). Long-standing concerns over unsustainable increases in healthcare spending led to passage of the Affordable Care Act in 2010, which within the first 3 years of implementation (2013-2016) contributed to a decline in the number of uninsured Americans by 18.5 million (Skopec et al., 2018). While U.S. legislation prohibits use of cost thresholds in healthcare policy decisions, the proportion of the gross domestic product being spent on healthcare forces policy makers to at least consider the costs within the context of the effectiveness of new treatments, devices, or interventions (Neumann et al., 2014). Health policy makers increasingly request analyses, including projected economic outcomes, prior to the approval of funding for or reimbursement of these new activities.

At the same time that the focus on cost has increased, other factors have also raised the importance of studying and contemplating the cost-effectiveness of healthcare in the United States. These include (a) the issuance of scientific recommendations for the conduct of cost-effectiveness analyses in the United States, (b) a format for formulary submissions offered by the Academy of Managed Care Pharmacy, (c) recognition by parties in the United States of cost-effectiveness recommendations around the globe, (d) conferences related to cost-effectiveness sponsored by the National Institute of Nursing Research, and (e) the continued emphasis on use of comparative-effectiveness methodology by the Patient-Centered Outcomes Research Institute (PCORI) to improve the quality of evidence available to inform healthcare decision-making (PCORI, 2020). Making decisions about which healthcare interventions to implement necessarily occurs across settings. Resources are always limited; money spent in one place cannot be spent in another. Stakeholders at all levels continuously decide how to allocate their budgets and which intervention or treatment will give them the greatest outcome for their resources, or "bang for their buck." At a societal level, policy makers must decide where to allocate resources because money spent on healthcare cannot be spent on education or transportation, for example. Similarly, at an organization level, nurse administrators are making decisions such as which infection prevention protocol or staffing ratio to implement to achieve the best patient outcomes within the constrained resources they have.

Therefore, in the current economic and healthcare environment, APRNs need to be knowledgeable about the interpretation of cost, and effectiveness data in particular, when they are combined in a cost-effectiveness study. The increased demand for economic information has resulted in a number of economic evaluations in the literature specific to nursing and a plethora of cost-effectiveness studies (e.g., Bryant-Lukosius et al., 2015; Cohen et al., 2016; Hutton et al., 2018; Martin-Misener et al., 2015; Twigg et al., 2015). Not only are APRNs and other clinicians now expected to review publications containing economic outcomes related to their services, but they must also participate in these analyses and interpret others for appropriateness of implementing findings into practice.

To accomplish these goals, APRNs must understand how to distinguish comparative-effectiveness research from cost-effectiveness analysis (CEA) research and business case analyses. Comparative-effectiveness research has been defined as the conduct and synthesis of research comparing the benefits and harms of different interventions and strategies to prevent, diagnose, treat, and monitor health conditions in "real-world" settings; its purpose is to improve health outcomes by developing and disseminating evidence-based 
information about the everyday effectiveness of interventions (Federal Coordinating Council for Comparative Effectiveness Research, 2009; Iglehart, 2009; Volpp \& Das, 2009). This is in contrast to efficacy research, such as a randomized controlled trial, where the question is typically whether the treatment can work under a controlled environment. Because comparative-effectiveness research is aimed to inform actual patient situations, it is very much patient centered and thus is also called patient-centered outcomes research. This methodology not only highlights the everyday needs of the patients, but may also incorporate many different types of patient outcomes. Cost-effectiveness research is one type of patient-centered outcomes research that focuses on economic outcomes of two or more comparable healthcare interventions and is well suited to be conducted alongside a comprehensive comparative-effectiveness assessment (Garber, 2011; Jacobson, 2007; Stone, 2001a, 2001b). In contrast to both of these, a business case analysis is generally from the more narrow perspective of a single organization that may choose to implement an intervention or not. This focuses on the costs and revenue generated for a single organization (and describes data on any health outcomes that are relevant to the organization) and uses an organization's view of the future to compare costs and revenue now with costs and revenue later to calculate return on investment and make an inference about whether to implement the intervention.

Different methods are employed to address economic outcomes of healthcare to inform policy or recommendations for adoption. The purposes of this chapter are to (a) present an overview of five different types of economic evaluations an APRN may encounter, (b) discuss appropriate outcome measures for each type of analysis, (c) present and critique published examples of each type of economic evaluation, and (d) discuss methodological issues of importance to economic evaluations.

\section{TYPES OF ECONOMIC EVALUATIONS}

Five different methods of economic evaluations are commonly used in assessing the economic impact of new healthcare interventions and technology. Table 2.1 presents a brief overview of these methods (Drummond et al., 2015). In all of these economic outcome evaluations, alternative strategies are compared and the incremental cost of the competing strategies is computed according to the following formula:

$$
\text { Incremental costs }=C 1-C 2
$$

where $C 1$ represents the cost of the new intervention and $C 2$ represents the cost of the comparator (e.g., the next best strategy). There is more variation between methods regarding how effectiveness is measured, although the focus remains on incremental changes in effectiveness (e.g., comparing the outcome of one intervention with that of another).

\section{Cost-Minimization Analysis}

In a true cost-minimization analysis (CMA), only the costs are evaluated and the alternatives are assumed or have been found to offer equivalent outcomes. Many of these studies begin as cost-effectiveness studies, in which the investigators expected one inter- 
TABLE 2.1 Types of Economic Evaluations

\begin{tabular}{|c|c|c|}
\hline TYPE OF STUDY & DEFINITION & OUTCOME \\
\hline $\begin{array}{l}\text { Cost-minimization } \\
\text { analysis (CMA) }\end{array}$ & $\begin{array}{c}\text { An analysis that computes the incremental costs } \\
\text { of alternatives that achieve the same effect }\end{array}$ & Monetary \\
\hline $\begin{array}{l}\text { Cost-consequence } \\
\text { analysis (CCA) }\end{array}$ & $\begin{array}{l}\text { An analysis in which incremental costs and } \\
\text { multiple effects are computed, without any } \\
\text { attempt to aggregate them }\end{array}$ & $\begin{array}{l}\text { Dollars per natural occur- } \\
\text { ring unit* }\end{array}$ \\
\hline $\begin{array}{l}\text { Cost-effectiveness } \\
\text { analysis (CEA) }\end{array}$ & $\begin{array}{l}\text { An analysis in which incremental costs and one } \\
\text { type of effects are presented in a ratio }\end{array}$ & $\begin{array}{l}\text { Dollars per natural occur- } \\
\text { ring unit* }\end{array}$ \\
\hline $\begin{array}{l}\text { Cost-utility analysis } \\
\text { (CUA) }\end{array}$ & $\begin{array}{l}\text { A specific type of CEA, in which effect on quality } \\
\text { of life is considered and a metric is used that } \\
\text { combines quality and quantity of life }\end{array}$ & $\begin{array}{l}\text { Dollars per quality-adjusted } \\
\text { life year }\end{array}$ \\
\hline $\begin{array}{l}\text { Cost-benefit analysis } \\
\text { (CBA) }\end{array}$ & $\begin{array}{l}\text { An analysis in which incremental costs and } \\
\text { effects are computed, and all benefits and } \\
\text { costs are measured in a single currency such } \\
\text { as } 2020 \text { U.S. dollars }\end{array}$ & Monetary \\
\hline
\end{tabular}

*Examples of natural occurring units are life years gained, disability days saved, or cases avoided.

vention to be both more effective and more expensive. As a result, in most published economic evaluations labeled as CMAs, clinical outcomes of the strategies being compared are measured (e.g., McClean et al., 2018; Van Der Biezen et al., 2016). For example, after establishing similar patient outcomes for a weekend on-call practice group of nurse practitioners compared to a practice group of physicians, Van Der Biezen et al. (2016) then used data from the trial to conduct a CMA. They determined that, from the perspective of the Netherlands healthcare system, the nurse practitioner group had lower costs. In the McClean et al. (2018) study, a comparison of costs for transcutaneous versus total serum bilirubin measurement in infants in both hospital and community settings was conducted using administrative data from the health system. While both approaches are effective in identifying newborn jaundice, the transcutaneous approach was cost saving because it reduced nurses' time to conduct the screening and provide results.

\section{Cost-Consequence Analysis}

A cost-consequence analysis (CCA) is a study in which the costs and the consequences of two or more alternatives are measured, but costs and consequences are listed separately. This methodology is often chosen when there is no obvious summary measure for the outcomes applicable to the interventions being studied. In a CCA, the analyst expects the decision makers to form their own opinions about the relative importance of the findings. To facilitate decision-making, the analysts provide an array of consequences applicable to each strategy. Two studies serve as examples of this methodology being used in the nursing literature. Schoonhoven et al. (2015) compared the consequences of using bed baths or traditional soap and water baths for nursing home residents in a cluster randomized trial that assessed resident skin integrity, resident behavioral problems, costs, and resident 
and nurse satisfaction. Campbell et al. (2014) determined the costs and consequences of increasing primary care access (operationalized as the number of patient contacts) comparing usual care to (a) general practitioner telephone consultation or (b) nurse telephone consultation.

\section{Cost-Effectiveness Analysis}

CEA also measures incremental costs. In CEA, incremental consequences are measured in a single common natural unit, such as life years gained or cases avoided. In addition, costs and effects are summarized in an incremental cost-effectiveness ratio (ICER), which is calculated using the following formula:

$$
\text { Incremental cost-effectiveness ratio }=(C 1-C 2) /(E 1-E 2)
$$

where $C 1$ represents the cost of the new intervention, $C 2$ represents the cost of the comparator, $E 1$ represents the effect of the new intervention, and $E 2$ represents the effect of the comparator. For CEA, analysts often attach the resource utilization data-collection process to a randomized trial, usually powered on something other than the cost-effectiveness result (e.g., Jeon et al. [2015] examined nurse work environment and outcomes in older adults), or employ a decision-analytical approach and model the problem through the use of a decision tree (e.g., Kang et al. [2012] examined different methods of monitoring for methicillin-resistant Staphylococcus aureus in academic hospitals; Fatoye and Haigh [2016] compared ankle brace use vs. taping on patients returning to work after an acute ankle sprain).

The decision is between choosing alternative 1 and alternative 2. Both alternatives have associated probabilities of positive (good) and negative (bad) outcomes. In addition, there are the associated costs of each strategy. The use of decision analysis and decision trees is a defined mathematical modeling technique. A sample decision tree is diagrammed in Figure 2.1. It is suggested that anyone interested in using this technique seek training opportunities. There are a number of highly readable texts available to the APRN wishing to understand this approach better (Drummond et al., 2015; Hunink et al., 2014; Neumann et al., 2016).

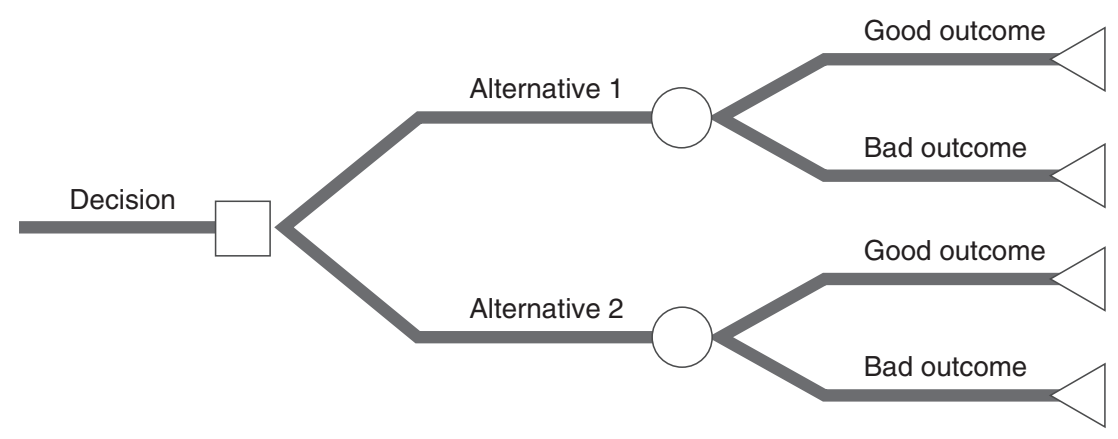

FIGURE 2.1 Example of a decision tree, where the probability of a good or bad outcome for each alternative intervention is used to calculate the optimal decision. 
A number of examples of CEA can be found in nursing literature (Hunter, 2015; Jeon et al., 2015; Kang et al., 2012). Jeon et al. (2015) provide an excellent example of deriving a CEA from a cluster randomized controlled trial. The study sought to improve care of older adults through a year-long management skills intervention among nurse managers focused on the work environment, measured by the Work Environment Scale-R (WES-R) score and the Multifactor Leadership Questionnaire (MLQ)-Rater form. The cost of the intervention was monitored as a secondary outcome, the results of which were expressed as mean ICER. The intervention resulted in a one-point increased mean score in transformational leadership per \$1,584 AUD (Australian dollars) spent and a one-point increased mean score in overall leadership per \$1,343 AUD spent. Although these are acceptable health outcomes, use of the WES-R score and MLQ-Rater form only facilitates comparison with other studies that also focus on interventions for work environment. In contrast, Hunter (2015) used a Markov model (i.e., simulating what happens to a cohort of individuals over multiple periods through time) to estimate the cost-effectiveness of three alternatives to promote antibiotic stewardship for respiratory illness in primary care: standard practice, c-reactive protein point of care testing, and this testing with added communication training. For each option, the author calculated the probability of antibiotic prescribing and the number of respiratory illnesses.

\section{Cost-Utility Analysis}

Cost-utility analysis (CUA) considers the effectiveness of the interventions on both the quantity and the quality of life in a single measure, the quality-adjusted life year (QALY). The QALY is a measure of the quantity of life gained weighted by the quality of that life. Quality of life is measured by a utility, which is a measure of preference for a given health state rated on a scale of 0 (death) to 1 (perfect health). Because dollars spent to gain a QALY are not disease specific, the measure is useful for informing health policy decisions and is recommended for such use by the U.S. Public Health Service's Panel on Cost-Effectiveness in Health and Medicine (Neumann et al., 2016). The QALY is a common outcome unit at this point in time, as it has been recommended by a number of organizations around the world and facilitates comparisons among different studies.

However, variance in the interpretation of what QALYs are actually measuring exists and estimates for the value of a QALY have ranged from $\$ 20,000$ to $\$ 200,000$ ("Determinants of health economic decisions in actual practice: The role of behavioral economics," 2006; Neumann et al., 2014). The willingness-to-pay threshold, or the limit society is willing to pay to gain one QALY, is not a well-defined number. In fact, a 2016 meeting of the International Society of Pharmacoeconomics and Outcomes Research (ISPOR) devoted a session to whether more evidence is needed for cost-effectiveness thresholds and, if so, how to generate this evidence (ISPOR, 2016). While lack of universal agreement as to what society should be willing to pay to gain a QALY persists, and despite specific U.S. legislation against use of a cost-per-QALY threshold, the figure of $\$ 50,000$ to $\$ 100,000$ / QALY is often cited in the United States (Neumann et al., 2014).

Numerous examples exist in the nursing literature of cost-utility analyses. For example, Blakely et al. (2015) examined the cost-utility of a hospital-based nurse cancer care coordinator (vs. having no dedicated coordination service) for stage III colon cancer 
patients. They determined that the cost per QALY of this program was $\$ 15,600$, with increased coverage of chemotherapy and reduced time to treatment. If hypothetically a willingness-to-pay threshold of $\$ 50,000$ per QALY had been set a priori by stakeholders, we could say that "hospital-based nurse cancer care coordination is cost-effective at a willingness-to-pay of $\$ 50,000$ " because researchers found the cost per QALY to be less than $\$ 50,000$. In another CUA, Marsden et al. (2015) evaluated different repositioning strategies for the prevention of pressure ulcers from the perspective of the U.K. National Health Service and determined that while repositioning every 2 to 4 hours is slightly more effective, it is not more cost-effective at a threshold $£ 20,000$ per QALY than repositioning every 4 hours. This is an example of an intervention where the added effect was not large enough to justify the added cost.

\section{Cost-Benefit Analysis}

$\mathrm{CBA}$ is a form of economic evaluation in which consequences are summarized in monetary units. In CBA, a single monetary figure representing benefits minus costs is calculated. As long as the decision maker agrees with the methods used to place a dollar value on outcomes, this provides the decision maker with a direct indication of whether the value of the benefits is greater than the cost. Wang et al. (2014) used a CBA to help policy makers evaluate the value of the Massachusetts Essential School Health Services program, which employs and maintains an onsite, full-time, baccalaureate-prepared RN in every public school. By including costs of nurse staffing and medical supplies, and the savings (benefits) from reducing medical procedures and protecting teacher and parent productivity, the authors determined that the program yielded a net benefit of $\$ 98.1 \mathrm{mil}$ lion during the 2009 to 2010 school year (\$2.20 gained for every \$1 invested). Another study used CBA to determine if a safe patient-handling program in an outpatient rehabilitation center would prevent work-related injuries during patient transfers among nurses and other therapy staff. Implementing the program gained \$3.71 in benefit for every dollar invested in the program, although the injury reduction rates were not sustained (Theis \& Finkelstein, 2014).

\section{COMMON ISSUES IN ALL ECONOMIC EVALUATIONS}

The basic steps needed to conduct economic evaluations are illustrated in Figure 2.2. In addition, because this is essentially a new language to many APRNs, Table 2.2 defines some of the concepts and common terminology used in these analyses.

\section{Selecting the Type of Economic Evaluation}

The first step is to select the appropriate type of analysis to conduct. Considerations should include (a) the goal of the analysis (e.g., whether to compare only interventions affecting a single disease with a well-defined most important symptom or to compare interventions for different diseases or interventions for a condition with a complex set of symptoms), (b) whether the effectiveness of the interventions is equivalent (and, if so, this suggests a CMA), (c) the effectiveness measures available (e.g., can QALYs be generated?), (d) the 


\section{Select type of economic evaluation}

CBA, CCA, CMA, CUA, or CEA

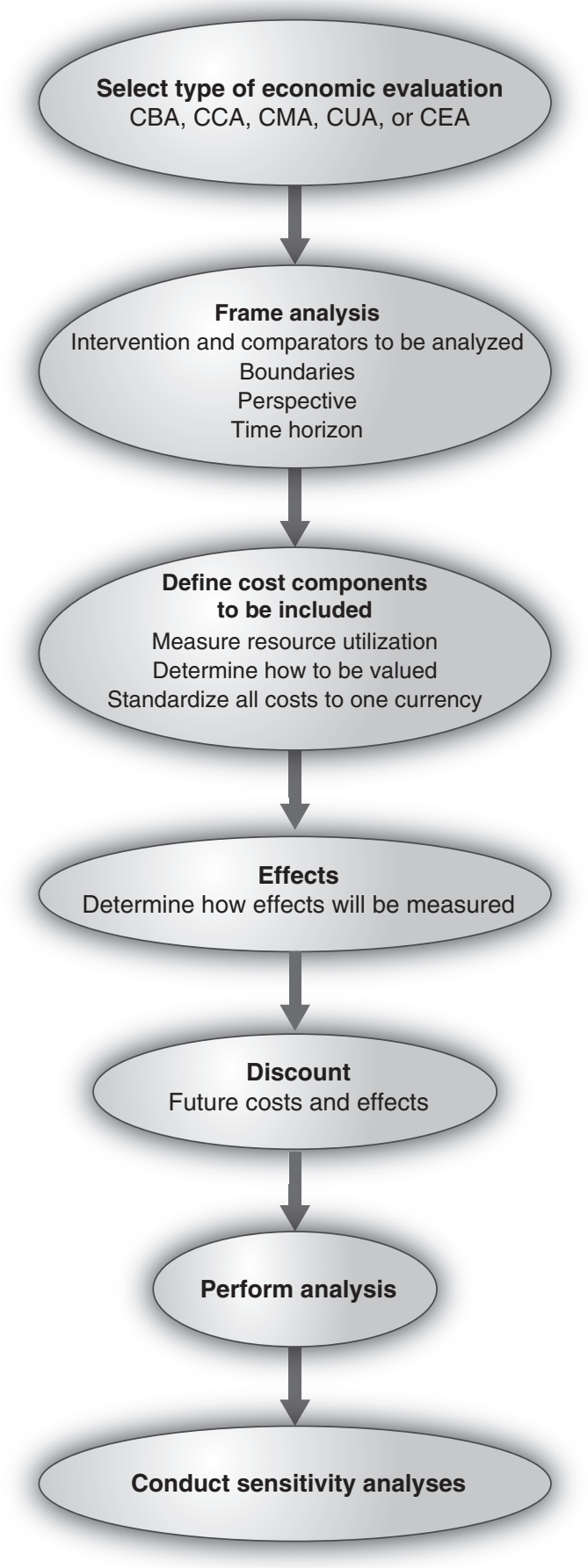

FIGURE 2.2 Basic steps in economic evaluations.

CBA, cost-benefit analysis; CCA, cost-consequence analysis; CEA, cost-effectiveness analysis; CMA, cost-minimization analysis; CUA, cost-utility analysis. 
TABLE 2.2 Common Terminology in Economic Evaluations

\begin{tabular}{|c|c|}
\hline TERM & DEFINITION \\
\hline Boundaries of the study & $\begin{array}{l}\text { The scope of the study with regard to which costs and outcomes are } \\
\text { included }\end{array}$ \\
\hline Comparator(s) & The alternative(s) to which the new intervention is compared \\
\hline Consumer price index (CPI) & $\begin{array}{l}\text { A measure of average change in price over time. This is used to adjust } \\
\text { costs that are estimated in different past years to the present }\end{array}$ \\
\hline Discounting & The process of converting future costs and effects to the present value \\
\hline $\begin{array}{l}\text { Incremental cost-effective- } \\
\text { ness ratio }\end{array}$ & $\begin{array}{l}\text { The ratio of the difference of the costs of two alternatives to the dif- } \\
\text { ference in effectiveness between the same two alternatives. Used in } \\
\text { cost-effectiveness and cost-utility analyses }\end{array}$ \\
\hline Perspective & The viewpoint from which the analysis is conducted \\
\hline Sensitivity analysis & $\begin{array}{l}\text { Calculations in which an input to the calculation (either measured or } \\
\text { assumed) is varied and indicates the degree of influence it has on } \\
\text { the analysis. Often used when a parameter is uncertain }\end{array}$ \\
\hline Time horizon & The period of time for which the costs and effects are measured \\
\hline
\end{tabular}

potential impact of the interventions on either quality or quantity of life (if both, then a CUA is most appropriate), (e) the availability of data, (f) the expertise available, and (g) ethical issues.

\section{Framing the Analysis}

Once the economic method has been selected, the researcher frames the analysis. This includes selecting the appropriate comparator(s) to analyze. For example, when testing the cost-effectiveness of a new educational program, the researcher might consider implementation in a hospital setting, initiation in an outpatient clinic, and a lack of teaching altogether as comparators given that outcomes may be different among them. At the least, the comparison of new interventions should be to the current practice, or status quo. Benchmarking to an established standard of care emphasizes the fact that analyses do not compare an intervention with "doing nothing." In addition, often more than one comparator is appropriate to include in the analysis. This is especially true when multiple alternatives have been found to offer similar clinical outcomes or if there are potentially multiple levels of intensity of the interventions (e.g., increasing home health visits from twice a week to daily).

Boundaries (i.e., the scope) of the study delimit the costs and effects that are included in the analysis. Many interventions have spillover effects that must be considered. The question becomes how far to follow such effects to adequately assess the economic impact of the intervention. For example, if the aim of an educational program for mothers of infants admitted to a NICU is to decrease the mothers' levels of anxiety and improve the physiologic outcomes of the infants, then it logically follows that the boundaries would include both the mothers and the infants. This intervention may affect the overall parenting skills of the mother, however, and may have additional positive effects on other children in the 
family. In theory, all these effects are relevant, but in framing the study it is important to draw practical and feasible limits around the analysis.

In all types of economic evaluations, the perspective or viewpoint taken in the analysis also drives the set of costs and benefits included. Studies may be motivated by policy decisions relevant to specific institutions or individuals. In this case, the perspective of primary interest may be that of a managed care organization, hospital, employer, state health department, or another party. An economic evaluation conducted from the perspective of the hospital (e.g., providing a result most relevant to a hospital decision maker) should not consider costs (or savings) associated with family caregiving in the home. If the goal of the analysis is to affect broad resource allocation and health policy issues, however, then the societal perspective is appropriate and recommended (Neumann et al., 2016). This perspective incorporates all costs and all health effects regardless of who incurs them. This is advantageous because, if a systematic analysis is performed to compare the results of multiple studies and all have used the societal perspective, it makes comparison easier. Gathering data for the societal perspective also allows any other perspective to be calculated as a subset of the societal perspective. Indeed, the Second Panel on Cost-Effectiveness in Health and Medicine recommends that two reference cases should be reported: one from the healthcare perspective and one from the societal perspective (Neumann et al., 2016).

The time horizon refers to the period of time for which the costs and benefits are measured in the analysis. The time horizon may vary from less than 1 year to the patient's entire life span. The appropriate time horizon to consider will depend on the probable length of effect of the interventions being compared. Once the framing of the analysis is complete, the analyst is ready to estimate costs. The distinction between the time of the intervention and the time horizon for the analysis must be kept in mind. An intervention that lasts less than 1 year (e.g., nurses providing counseling to adolescents on high-risk behaviors) may have effects that last a lifetime.

\section{Costs}

Terminology pertaining to costs of resources has traditionally been divided into "direct" and "indirect" costs (Gold et al., 1996), with other labels like "friction costs" sometimes being applied to the cost of hiring a new employee and sometimes being applied to an entire method of valuing productivity (Brouwer \& Koopmanschap, 2005; Gold et al., 1996). However, because economists and accountants do not use the same definitions and sometimes even economists have not been able to agree on a universal set of definitions, the terminology has become complicated. In health economics, direct costs have been defined as changes in resource use directly attributable to the provision of care, whereas indirect costs have been referred to costs associated with the loss of productivity from morbidity and/or mortality (Liljas, 1998). Accountants, on the other hand, refer to direct costs as variable costs (e.g., supplies) and indirect costs as fixed costs (e.g., rent; Young, 2012). In light of these past inconsistencies in defining and measuring costs, the APRN conducting an economic evaluation should be sure to clarify and clearly communicate how the cost terms are defined. The trend in the CEA literature is to avoid the term "indirect." Given this trend and the potential for confusion, we urge APRNs to likewise avoid using this term. 
Economists and analysts often use a "two-step" approach to determine the costs attributable to an intervention. The first step in the estimation is determining the amount of resources attributable or consumed. Once the attributable resources have been determined, the "money" valuation or costs of the resources may be estimated. Using a twostep approach increases the clarity and transparency of the analysis and allows readers of the analysis to understand how the costs of attributable resources may be similar or different in their own setting.

The resources and associated costs can be categorized as in Exhibit 2.1, which is an adaptation of a grouping from the Second Panel on Cost-Effectiveness in Health and Medicine Recommendations (Sanders et al., 2016). In CEA, formal healthcare costs are directly related to the intervention itself and associated costs or savings of future healthcare, which the intervention may impact. For example, healthcare costs associated with a hepatitis B virus (HBV) immunization program should include the costs of obtaining and administering the immunization. In addition, they should include "downstream" costs (as well as savings), such as hospitalizations, outpatient visits, and other treatment costs

\title{
EXHIBIT 2.1
}

\section{COST COMPONENTS TO CONSIDER FOR INCLUSION FROM THE SOCIETAL PERSPECTIVE}

\author{
Formal healthcare costs* \\ Intervention \\ Hospitalization \\ Outpatient visits \\ Long-term care \\ Other healthcare costs paid by third-party payers \\ Other out-of-pocket costs paid by patients \\ Informal healthcare costs \\ Patient time \\ Family/unpaid caregiver time \\ Transportation \\ Non-healthcare costs \\ Productivity \\ Consumption \\ Social services \\ Legal or criminal justice \\ Education \\ Housing \\ Environment \\ *Recommended for inclusion in cost-utility analysis from the healthcare sector perspective as well as the \\ societal perspective by the Second Panel on Cost-Effectiveness in Health and Medicine. \\ Source: From Sanders, G. D., Neumann, P. J., Basu, A., Brock, D. W., Feeny, D., Krahn, M., Kuntz, K. M., \\ Meltzer, D. O., Owens, D. K., Prosser, L. A., Salomon, J. A., Sculpher, M. J., Trikalinos, T. A., Russell, L. \\ B., Siegel, J. E., \& Ganiats, T. G. (2016). Recommendations for conduct, methodological practices, and \\ reporting of cost-effectiveness analyses: Second panel on cost-effectiveness in health and medicine. JAMA, \\ 316(10), 1093-1103. https://doi.org/10.1001/jama.2016.12195.
}


associated with the diagnosis of HBV itself. Formal costs associated with other related diseases, such as cirrhosis or cancer, should also be included. Similarly, the value of the time a patient spends either seeking care or participating in an intervention constitutes a real use of resources for the individual and society. Thus, relevant patient time costs, or informal healthcare costs, may include both the time involved in receiving the treatment and the time spent waiting to receive care.

Consumption of resources other than those associated with the provision of healthcare should also be considered in economic evaluations conducted from the societal perspective. Examples of non-healthcare costs may include child care costs for a parent attending a smoking cessation program, increase in a family's food expenditure as a result of a dietary prescription, decrease in legal costs due to a reduction in substance use, environmental costs of healthcare waste, and the like.

Historically, patient time and non-healthcare resources have not been consistently included in analyses (Jacobs \& Fassbender, 1998; Stone et al., 2000). Nonetheless, if an analysis is conducted from the societal perspective, inclusion of such factors is recommended (Neumann et al., 2016; Sanders et al., 2016). In addition, because healthcare is becoming more community based, nursing interventions may directly influence these costs. For example, a home visit by an APRN case manager may not only increase the ability of the APRN to conduct a holistic assessment, but may also save resources related to patient time, transportation, and family caregiving. Bhandari (2011) included patient transportation costs of an iron supplementation therapy in a cost-minimization study and found that new iron preparations reduced these costs compared to standard of care.

Productivity costs are the costs associated with morbidity or mortality. Morbidity costs are those associated with lost or impaired ability to work or to engage in leisure activities (e.g., loss of income due to time for recuperation or convalescence after coronary bypass surgery). Mortality costs are related to loss of life and are usually measured according to what the individual would have been capable of earning. Two issues are important to note concerning productivity costs.

First, the U.S. Public Health Service's Panel on Cost-Effectiveness in Health and Medicine recommended that productivity costs be excluded from CUAs (Gold et al., 1996). The authors expressed concern that including both productivity costs and QALYs would represent a double counting because people may be considering productivity and earning potential when responding to trade-offs involving health and quality of life. Thus, when QALYs are used, productivity is already included in the denominator of the costeffectiveness ratio.

Second, the assumption that productivity costs should be excluded from CUAs is controversial and has been debated by experts in the field (Krol et al., 2013). The most recent recommendations suggest that researchers include productivity costs in analyses from the societal perspective but not from the healthcare perspective, although they recognize this was a debate among the Panel and that double-counting may result (Sanders et al., 2016). In light of this controversy, some analysts have presented results both with and without the inclusion of productivity costs (Krahn et al., 1998; Moradi-Lakeh et al., 2012). APRNs conducting CUAs may also wish to present results both with and without the inclusion of productivity costs as well as continue to monitor recommendations made in the United States and elsewhere. 
Some interventions (e.g., a successful smoking cessation program) extend life. Costs related to resource consumption in "added life years" are recommended for inclusion in economic evaluations. Added life-year costs are related to the consumption of healthcare resources (financial healthcare costs) and other types of consumption (all other cost categories). Because not all analyses increase life expectancy (e.g., use of cochlear implants or an educational intervention program aimed at decreasing parental anxiety), resource consumption in added life years is not always applicable. Sometimes, living longer and healthier can cost less annually but sum to more over a lifetime (van Baal et al., 2008). Generally, only the added healthcare costs, not added general consumption, are included in the analysis.

Finally, income transfers, such as Social Security payments, are redistributions of money and are therefore not real costs to society. Consequently, although these "transfer costs" may be tracked and may be important for analyses from the government's perspective, they should not be included with other societal costs. What should be included in a societal cost analysis are the costs of administering an income transfer program.

When trying to determine which costs to include, the process should begin with an outline of the categories of costs included, using the list in Exhibit 2.1. Once this is complete, a researcher should consider the cost "ingredients" that the intervention impacts under each category (Drummond et al., 2015). After the ingredients are identified, discussions about which costs are most relevant and which are important to measure can take place. Moreover, the perspective of the analysis will drive the decisions about which cost component to include. The treatment of the cost component (e.g., productivity costs captured in qualityof-life adjustments) is determined by the specific economic-analytical method chosen.

Once the consumption of resources has been estimated, the resource must be assigned a dollar value. Economists use the term "opportunity costs," which reflect the value of the next best alternative use of the resources. Determining the actual opportunity cost of a resource is difficult. Following are some general guidelines for assigning a dollar value to a resource.

In many markets, market prices (or charges) equate to opportunity costs. This does not apply in healthcare as often as in other fields. This incongruence is particularly notable for charges associated with hospitalizations. Although healthcare institutions bill for standard amounts, some payers are able to successfully negotiate lower charges for care. However, payers who are willing to pay higher levels of reimbursement or unable to negotiate lower levels of reimbursement will ultimately pay more for the same care. The practice of obtaining higher payments from some patrons is termed "cost shifting." Therefore, for these institutional categories, an adjustment to prices is necessary to accurately represent exchange of funds, the cost. In fact, many customers, such as large insurance organizations, pay only a fraction of these charges. Large payers negotiate payment rates for services rendered based on the cost of the service and allowed profit margins (or excess revenues for notfor-profit institutions). Payers with the least market power (e.g., uninsured individuals) are the only ones who are likely to pay anything near the actual cost. If a hospital were just to break even based on the negotiated rates, then it is clear that the actual amount charged does not represent anything close to the actual cost.

Instead of using charges, a common source of valuation for hospital costs is the hospital's own cost-accounting system. For researchers internal to the institution, these will 
often be easy to access. These cost-accounting systems are developed by finance departments to help administrative decision-making and are based on past accounting studies and algorithms. Although the market price of medical care often does not represent actual costs, the market prices of the goods in the cost-accounting system are expected to represent the relevant costs of inputs to care. If a cost-accounting system is available, the APRN can usually determine the specific monetary healthcare cost components, such as variable costs (e.g., staffing and supplies) and fixed overhead costs (e.g., rent and percentage of administration costs).

Another alternative is to use hospital cost-to-charge ratios, which are calculated by dividing the total costs in a cost center by the total charges for the same resource. Costto-charge ratios are recognized as a gross adjustment to charges. This type of adjustment is better than using charges alone, but is not preferable to cost-accounting systems when they are available. Published sources also are often used as the source of valuation of the resource (Stone et al., 2000). Governmental fee schedules are also often used to represent costs of particular procedures (Agency for Healthcare Research and Quality, 2018).

When cost estimates come from various sources, it is important to standardize all costs to the same currency and year. For example, non-U.S. currency figures may be converted into U.S. dollars using the appropriate foreign exchange factor for that time period (Board of Governors of the Federal Reserve System, www.federalreserve.gov/releases/g5a/current/default.htm). A recent review article in the nursing literature demonstrates the concept of applying exchange rates to cost estimates to compare across geographic regions (Cohen et al., 2016). The concept of purchasing-power parity, which not only accounts for the exchange rate but also attempts to yield the capacity to purchase the same quantity of goods, is also commonly used (Penz et al., 2014). In addition, because $\$ 1$ in 1988 does not have the same purchasing power as $\$ 1$ in the year 2008, the costs from different years must be adjusted into a standard year format by the use of the consumer price index (CPI), for which U.S. data are available from the Bureau of Labor Statistics (BLS) website (www.bls. gov), and a single year-to-year calculation can be done using the inflation calculator provided at that website (data.bls.gov/cgi-bin/cpicalc.pl). This inflation calculator is based on general market goods inflation. An example of such adjustment is a recent review examining costs of infection prevention activities in long-term care facilities in which the authors converted reported costs into 2013 U.S. dollars so that costs from different studies could be compared more effectively (Cohen et al., 2016). The BLS also calculates a medical inflation rate (www.bls.gov/cpi/factsheets/medical-care.htm). Because the costs of healthcare are rising more rapidly than costs in most other markets, analysts often use the medical inflation rate to inflate costs that pertain only to healthcare resources. Finally, there is discussion as to whether to use the CPI or the producer price index for inflation adjustment in general. Again, this largely depends on perspective. True opportunity costs are likely to be reflected in the producer price index. However, if the perspective is a payer perspective, then the CPI is likely to be more appropriate.

\section{Discounting}

Once all costs and benefits have been calculated, future costs and benefits are discounted to present value. Discounting reflects the principle that suggests people place greater value 
on something they have today than on something they will have in the future. Interest rates are an example of this principle. Future costs and benefits are discounted to present value using the following formula:

$$
F /(1+r)^{n}
$$

where $F$ is the future value (usually measured in dollars at today's value), $r$ is the discount rate, and $n$ is the number of years in the future (Stone, 1998). Currently, in the United States, experts recommend using the same discount rate to discount both costs and effects (Neumann et al., 2016). However, because prevention interventions are aimed at improving future health, by discounting future benefits, the intervention may not seem as beneficial. Therefore, some analysts are uncomfortable discounting future health benefits and only discount costs (Stone et al., 2000). Thus, to increase the comparability of analyses, APRNs in the United States should discount both costs and effects at 3\% and, if desired, the results without discounting may also be presented. Moreover, the discount rate for a business case analysis is likely to be higher and represent the expected return on alternative uses of resources.

\section{Analysis}

In conducting economic evaluations, data gathered may include resource utilization, value of resources, effectiveness of treatment, and preferences regarding health outcomes. Based on the data gathered, the "base-case" analysis is computed. A best practice when presenting results is to include a table listing all parameters, the value assigned to each parameter, and the source of the value.

\section{Sensitivity Analysis}

Many of the data points gathered include some assumptions or uncertainty in the inputs. For clarification, the analysis based only on the best point estimates is referred to as the "base case," regardless of whether the recommendations of the panel are followed. Thus, any CEA includes a base case, but not all base-case analyses are reference-case analyses.

The assumptions that are made in the base case should be clearly stated before the results are presented to increase the transparency of the analysis. In addition, sensitivity analyses should be conducted to explore the implications of alternative assumptions. Sensitivity analysis is an important element of a sound economic evaluation (Drummond et al., 2015; Gold et al., 1996).

Sensitivity analyses are calculations in which a parameter is varied. These analyses indicate the degree of influence the particular value has on the analysis. The range used for a parameter should be specified along with the point estimate in Table 2.2.

A univariate sensitivity analysis examines the degree to which changing a single assumption changes the outcome of the entire analysis. By varying the value of the variable over a reasonable set of parameters, the investigator is able to determine how that variable may impact the results under different assumptions. The impact on the results has multiple interpretations. One is how the magnitude of the cost-effectiveness ratio changes. in other words, whether the ratio changes from spending \$10,000/QALY gained 
to $\$ 30,000 /$ QALY gained. However, a second level of interpretation is whether the decision to implement or not implement a new intervention changes. If a decision maker believes that any program costing less than $\$ 50,000$ is a candidate for implementation, then the change from \$10,000/QALY to \$30,000/QALY will not change the decision about whether to consider a new intervention for implementation. Ryan et al. (2013) used a series of univariate sensitivity analyses to explore the extent of cost minimization between midwife-led maternity care and midwife care for only low-risk cases across the United Kingdom. Taking parameter estimates from three different clinical studies, the authors generated and evaluated eight different possible scenarios and determined that the cost difference between the alternatives ranged from $-£ 253.38$ to $£ 108.12$ per case.

Although univariate sensitivity analyses are insightful, looking at one source of uncertainty by itself is usually inadequate. The alternative is multivariate sensitivity analysis. A multivariate sensitivity analysis examines multiple sources of uncertainty at one time and may generate a more accurate understanding of the uncertainty of the cost-effectiveness results. This can be done by changing all parameters to their most or least favorable levels-but still working with predetermined levels of the values for each variable. A second approach makes use of the fact that variables can sometimes be expected to change together; in such cases, the analyst might explore how the cost-effectiveness ratio changes as the two variables are varied over their ranges.

Finally, an analyst can conduct what is referred to as a probabilistic sensitivity analysis. In this case, the analyst must define distributions from which the values for parameters may be drawn. A random draw is then taken from each distribution and the results of the analysis are calculated. The results of the first analysis are recorded and the process is repeated-at least thousands and sometimes tens of thousands of times. The analyst must then describe the range of results by describing the distribution of ratios. Fatoye and Haigh (2016) used this technique to describe the distribution of cost-effectiveness results in a study to compare the use of semirigid ankle brace versus taping to prevent recurrent acute ankle sprains. In this study, the estimated mean costs were assumed to have normative distributions, thereby identifying a range of possible cost values to be included in the Monte Carlo simulation model. The authors found that although taping was less expensive, the ICER for the brace versus taping was $£ 263 /$ QALY (well below the recommended ICER). However, due to skewed willingness to pay, there was a $46 \%$ probability of cost-effectiveness. A decision maker faced with this information would have to determine whether being $46 \%$ certain of a favorable economic result is sufficient to move forward with a policy change.

\section{SUMMARY}

The checklist in Exhibit 2.2 may be useful when communicating the results of an economic evaluation. This checklist draws on criteria for high-quality cost-effectiveness studies and draws on a number of sets of criteria that have been specified in related literature (Drummond et al., 2015; Eldessouki \& Smith, 2012; Gold et al., 1996).

A second checklist for economic evaluations is the Consolidated Health Economic Evaluation Reporting Standards (CHEERS). This checklist, shown in Exhibit 2.3, may be particularly useful when reading and evaluating reported economic analyses, as well as designing and publishing these analyses (Husereau et al., 2013). 


\section{EXHIBIT 2.2}

\section{COST-EFFECTIVENESS ANALYSIS CHECKLIST FOR JOURNAL REPORT}

\section{Framework}

$\square$ Background of the problem

$\square$ General framing and design of the problem

$\square$ Target population for the intervention

$\square$ Other program descriptors

$\square$ Description of comparator programs

$\square$ Boundaries of the analysis

$\square$ Time horizon

$\square$ Statement of the perspective of the analysis

\section{Data and methods}

$\square$ Description of event pathway

$\square$ Identification of outcomes of interest in the analysis

$\square$ Description of model used

$\square$ Modeling assumptions

$\square$ Diagram of event pathway/model

$\square$ Software used

$\square$ Complete information about the sources of effectiveness data, cost data, and preference weights

$\square$ Methods for obtaining estimates of effectiveness, costs, and preferences

$\square$ Critique of data quality

$\square$ Statement of year costs

$\square$ Statement of method used to adjust costs for inflation

$\square$ Statement of type of currency

$\square$ Sources and methods for obtaining expert judgment

$\square$ Statement of discount rates

\section{Results}

$\square$ Results of model validation

$\square$ Reference-case results (discounted and undiscounted): total costs and effectiveness, incremental costs and effectiveness, and incremental cost-effectiveness ratios

$\square$ Results of sensitivity analyses

$\square$ Other estimates of uncertainty, if available

$\square$ Graphical representation of cost-effectiveness results

$\square$ Aggregate cost and effectiveness information

$\square$ Disaggregated results, as relevant

$\square$ Secondary analyses using 3\% discount rate

$\square$ Other secondary analyses, as relevant

\section{Discussion}

$\square$ Summary of reference-case results

$\square$ Summary of sensitivity analysis assumptions having important ethical implications

$\square$ Limitations of the study

$\square$ Relevance of the study results for specific policy questions or decisions

$\square$ Results of related CEAs

$\square$ Distributive implications of the intervention

\section{Technical report available upon request}

CEA, cost-effectiveness analysis.

Source: Adapted from Gold, M. R., Siegel, J. E., Russell, L. B., \& Weinstein, M. C. (1996). Cost effectiveness in health and medicine. Oxford University Press. 


\section{EXHIBIT 2.3}

\section{CHEERS CHECKLIST FOR JOURNAL REPORT}

\begin{tabular}{|c|c|c|c|}
\hline SECTION/TOPIC & \# & RECOMMENDATION & $\begin{array}{l}\text { REPORTED ON } \\
\text { PAGE NO./ } \\
\text { LINE NO. }\end{array}$ \\
\hline \multicolumn{4}{|l|}{ Title } \\
\hline Title & 1 & $\begin{array}{l}\text { Identify the study as an economic evaluation, } \\
\text { or use more specific terms such as "cost-ef- } \\
\text { fectiveness" and describe the interventions } \\
\text { compared }\end{array}$ & \\
\hline \multicolumn{4}{|l|}{ Abstract } \\
\hline Structured summary & 2 & $\begin{array}{l}\text { Provide a structured summary of objectives, } \\
\text { perspective, setting, methods (including study } \\
\text { design and inputs), results (including base-case } \\
\text { and uncertainty analyses), and conclusions }\end{array}$ & \\
\hline \multicolumn{4}{|l|}{ Introduction } \\
\hline $\begin{array}{l}\text { Background and } \\
\text { objectives }\end{array}$ & 3 & $\begin{array}{l}\text { Provide an explicit statement of the broader con- } \\
\text { text for the study. Present the study question } \\
\text { and its relevance for health policy or practice } \\
\text { decisions }\end{array}$ & \\
\hline \multicolumn{4}{|l|}{ Methods } \\
\hline $\begin{array}{l}\text { Target population and } \\
\text { subgroups }\end{array}$ & 4 & $\begin{array}{l}\text { Describe characteristics of the base-case popula- } \\
\text { tion and subgroups }\end{array}$ & \\
\hline Setting and location & 5 & $\begin{array}{l}\text { State relevant aspects of the system(s) in which } \\
\text { the decision(s) need(s) to be made }\end{array}$ & \\
\hline Study perspective & 6 & $\begin{array}{l}\text { Describe the perspective of the study and relate } \\
\text { this to the costs being evaluated }\end{array}$ & \\
\hline Comparators & 7 & $\begin{array}{l}\text { Describe the interventions or strategies being } \\
\text { compared and state why they were chosen }\end{array}$ & \\
\hline Time horizon & 8 & $\begin{array}{l}\text { State the time horizon(s) over which costs and } \\
\text { consequences are being evaluated and say } \\
\text { why appropriate }\end{array}$ & \\
\hline Discount rate & 9 & $\begin{array}{l}\text { Report the choice of discount rate(s) used for } \\
\text { costs and outcomes and say why appropriate }\end{array}$ & \\
\hline $\begin{array}{l}\text { Choice of health } \\
\text { outcomes }\end{array}$ & 10 & $\begin{array}{l}\text { Describe what outcomes were used as the mea- } \\
\text { sure(s) of benefit in the evaluation and their } \\
\text { relevance for the type of analysis performed }\end{array}$ & \\
\hline $\begin{array}{l}\text { Measurement of } \\
\text { effectiveness }\end{array}$ & $11 \mathrm{a}$ & $\begin{array}{l}\text { Single study-based estimates: Describe fully } \\
\text { the design features of the single effectiveness } \\
\text { study and why the single study was a sufficient } \\
\text { source of clinical effectiveness data }\end{array}$ & \\
\hline
\end{tabular}




\section{EXHIBIT 2.3}

\section{CHEERS CHECKLIST FOR JOURNAL REPORT (CONTINUED)}

\begin{tabular}{|c|c|c|c|}
\hline SECTION/TOPIC & \# & RECOMMENDATION & $\begin{array}{l}\text { REPORTED ON } \\
\text { PAGE NO./ } \\
\text { LINE NO. }\end{array}$ \\
\hline & $11 b$ & $\begin{array}{l}\text { Synthesis-based estimates: Describe fully the } \\
\text { methods used for identification of included } \\
\text { studies and synthesis of clinical effectiveness } \\
\text { data }\end{array}$ & \\
\hline $\begin{array}{l}\text { Measurement/ } \\
\text { valuation of } \\
\text { preference-based } \\
\text { outcomes }\end{array}$ & 12 & $\begin{array}{l}\text { If applicable, describe the population and meth- } \\
\text { ods used to elicit preferences for outcomes }\end{array}$ & \\
\hline \multirow[t]{2}{*}{$\begin{array}{l}\text { Estimating resources } \\
\text { and costs }\end{array}$} & $13 a$ & $\begin{array}{l}\text { Single study-based economic evaluation: De- } \\
\text { scribe approaches used to estimate resource } \\
\text { use associated with the alternative interven- } \\
\text { tions. Describe primary or secondary research } \\
\text { methods for valuing each resource item in } \\
\text { terms of its unit cost. Describe any adjustments } \\
\text { made to approximate to opportunity costs }\end{array}$ & \\
\hline & $13 b$ & $\begin{array}{l}\text { Model-based economic evaluation: Describe } \\
\text { approaches and data sources used to estimate } \\
\text { resource use associated with model health } \\
\text { states. Describe primary or secondary research } \\
\text { methods for valuing each resource item in } \\
\text { terms of its unit cost. Describe any adjustments } \\
\text { made to approximate to opportunity costs }\end{array}$ & \\
\hline $\begin{array}{l}\text { Currency, price, date, } \\
\text { and conversion }\end{array}$ & 14 & $\begin{array}{l}\text { Report the dates of the estimated resource } \\
\text { quantities and unit costs. Describe methods } \\
\text { for adjusting estimated unit costs to the } \\
\text { year of reported costs if necessary. Describe } \\
\text { methods for converting costs into a common } \\
\text { currency base and the exchange rate }\end{array}$ & \\
\hline Choice of model & 15 & $\begin{array}{l}\text { Describe and give reasons for the specific type } \\
\text { of decision-analytical model used. Providing } \\
\text { a figure to show model structure is strongly } \\
\text { recommended }\end{array}$ & \\
\hline Assumptions & 16 & $\begin{array}{l}\text { Describe all structural or other assumptions } \\
\text { underpinning the decision-analytical model }\end{array}$ & \\
\hline Analytical methods & 17 & $\begin{array}{l}\text { Describe all analytical methods supporting the } \\
\text { evaluation. This could include methods for } \\
\text { dealing with skewed, missing, or censored } \\
\text { data; extrapolation methods; methods for } \\
\text { pooling data; approaches to validate or make } \\
\text { adjustments (e.g., half-cycle corrections) to a } \\
\text { model; and methods for handling population } \\
\text { heterogeneity and uncertainty }\end{array}$ & \\
\hline
\end{tabular}




\section{EXHIBIT 2.3}

\section{CHEERS CHECKLIST FOR JOURNAL REPORT (CONTINUED)}

\begin{tabular}{|c|c|c|c|}
\hline SECTION/TOPIC & \# & RECOMMENDATION & $\begin{array}{l}\text { REPORTED ON } \\
\text { PAGE NO./ } \\
\text { LINE NO. }\end{array}$ \\
\hline \multicolumn{4}{|l|}{ Results } \\
\hline Study parameters & 18 & $\begin{array}{l}\text { Report the values, ranges, references, and, if } \\
\text { used, probability distributions for all param- } \\
\text { eters. Report reasons or sources for distri- } \\
\text { butions used to represent uncertainty where } \\
\text { appropriate. Providing a table to show the } \\
\text { input values is strongly recommended }\end{array}$ & \\
\hline $\begin{array}{l}\text { Incremental costs and } \\
\text { outcomes }\end{array}$ & 19 & $\begin{array}{l}\text { For each intervention, report mean values for the } \\
\text { main categories of estimated costs and out- } \\
\text { comes of interest, as well as mean differences } \\
\text { between the comparator groups. If applicable, } \\
\text { report incremental cost-effectiveness ratios }\end{array}$ & \\
\hline \multirow[t]{2}{*}{$\begin{array}{l}\text { Characterizing uncer- } \\
\text { tainty }\end{array}$} & $20 a$ & $\begin{array}{l}\text { Single study-based economic evaluation: De- } \\
\text { scribe the effects of sampling uncertainty for } \\
\text { the estimated incremental cost and incremen- } \\
\text { tal effectiveness parameters, together with the } \\
\text { impact of methodological assumptions (e.g., } \\
\text { discount rate, study perspective) }\end{array}$ & \\
\hline & $20 b$ & $\begin{array}{l}\text { Model-based economic evaluation: Describe } \\
\text { the effects on the results of uncertainty for all } \\
\text { input parameters, and uncertainty related to } \\
\text { the structure of the model and assumptions }\end{array}$ & \\
\hline $\begin{array}{l}\text { Characterizing hetero- } \\
\text { geneity }\end{array}$ & 21 & $\begin{array}{l}\text { If applicable, report differences in costs, } \\
\text { outcomes, or cost-effectiveness that can be } \\
\text { explained by variations between subgroups of } \\
\text { patients with different baseline characteristics } \\
\text { or other observed variability in effects that are } \\
\text { not reducible by more information }\end{array}$ & \\
\hline \multicolumn{4}{|l|}{ Discussion } \\
\hline $\begin{array}{l}\text { Study findings, lim- } \\
\text { itations, generaliz- } \\
\text { ability, and current } \\
\text { knowledge }\end{array}$ & 22 & $\begin{array}{l}\text { Summarize key study findings and describe how } \\
\text { they support the conclusions reached. Discuss } \\
\text { limitations and the generalizability of the } \\
\text { findings and how the findings fit with current } \\
\text { knowledge }\end{array}$ & \\
\hline \multicolumn{4}{|l|}{ Other } \\
\hline Sources of funding & 23 & $\begin{array}{l}\text { Describe how the study was funded and the role } \\
\text { of the funder in the identification, design, con- } \\
\text { duct, and reporting of the analysis. Describe } \\
\text { other nonmonetary sources of support }\end{array}$ & \\
\hline
\end{tabular}




\section{EXHIBIT 2.3}

\section{CHEERS CHECKLIST FOR JOURNAL REPORT (CONTINUED)}

\begin{tabular}{|l|l|l|l|}
\hline SECTION/TOPIC & $\#$ & RECOMMENDATION & $\begin{array}{l}\text { REPORTED ON } \\
\text { PAGE NO./ } \\
\text { LINE NO. }\end{array}$ \\
\hline Conflicts of interest & 24 & $\begin{array}{l}\text { Describe any potential for conflict of interest of } \\
\text { study contributors in accordance with journal } \\
\text { policy. In the absence of a journal policy, we } \\
\text { recommend authors comply with International } \\
\text { Committee of Medical Journal Editors recom- } \\
\text { mendations }\end{array}$ & \\
\hline
\end{tabular}

CHEERS, Consolidated Health Economic Evaluation Reporting Standards.

Source: Adapted from Husereau, D., Drummond, M., Petrou, S., Carswell, C., Moher, D., Greenberg, D., Augustovski, F., Briggs, A. H., Mauskopf, J., \& Loder, E. (2013). Consolidated Health Economic Evaluation Reporting Standards (CHEERS) statement. The European Journal of Health Economics, 14(3), 367-372. https://doi.org/10.1007/s10198-013-0471-6.

With the continuing development of new treatments, technologies, and models of care delivery, health-economic evaluations have become increasingly important. The demand for economic outcome research is growing, as is the number of published analyses. In this chapter, we have introduced several methods used in economic evaluation and have described the concepts and terminology used in these analyses.

The quality of studies has been variable and not necessarily improving. As more studies are conducted and submitted for peer-reviewed publication, editors are not always able to find reviewers with the appropriate expertise; hence, studies that are poorly conducted in general or for which specific elements are poor can make their way into print. APRNs who plan to read these analyses need to understand the methodology enough to recognize what makes a good study and what makes a study that is barely acceptable or even fails the test of acceptability.

APRNs interested in exploring this type of outcome evaluation are encouraged to seek additional training in these methods.

If APRNs participate in and conduct economic evaluations concerning the care they provide, the cost-effectiveness of APRN care may be demonstrated. When the analysis uses a standard methodology and the assumptions are transparent, the results are more easily interpreted. If the outcome measure is a standard ratio, such as dollars per QALY gained, the results may furnish a strong argument to health policy decision makers concerning the funding and continued recognition of APRNs as cost-effective healthcare providers.

\section{ANSWERS TO CHAPTER DISCUSSION QUESTIONS}

1. Both comparative effectiveness and cost-effectiveness are forms of research that determine relative effectiveness of an intervention, diagnostic procedure, or preventive strategy in a real-world environment. Cost-effectiveness 
methodology contrasts two or more interventions by including economic outcome(s). Comparative-effectiveness methodology compares a potentially broader range of benefits and harms in the everyday environment, but does not necessarily include economic outcomes or analysis. A business case analysis focuses on monetary outcomes for a single organization using the organization's own comparison of current and future costs and revenue. Relevant healthcare results are described but not included directly in a calculation.

2. CUA presents outcomes in terms of cost per QALY gained. Therefore, scenarios in which quality of life, mortality, as well as cost are of interest would be appropriate. For example, Biesheuvel-Leliefeld et al. (2012) designed a cost-utility study to test the quality-of-life improvement of a nursing-led intervention for recurrent major depressive disorder, and reported in cost per QALY gained.

3. Cost-consequence methodology is intended for subjects with multiple relevant outcome measures, often when these outcomes cannot be summarized into a single measure. Cost and consequences are listed from each intervention of interest in the results and analysis.

4. CBA requires that the benefits of the tested interventions be monetized. Therefore, a researcher must assume a particular monetary value that accurately represents derived benefit or QALY gained, which may be controversial. The outcome measure for CBA is a dollar amount that is the sum of all costs minus the benefits. In this way, the costs and benefits are compared in the same units, which is particularly helpful if potential benefits include nonclinical parameters (Riegelman, 2012).

5. The first step is to identify all the factors that will influence the total cost of the therapy. These may include the price of the antibiotic itself, the nurse's time for preparation, the patient's time in the clinical setting, and any physical materials for preparation (e.g., needle, syringe, tubing) depending on the study perspective. Benefits may include shortened time in the hospital, reduced complications, and fewer rehospitalizations. The second step would be assigning a dollar value to each cost and benefit, as exemplified in the methods of Weiss et al. (2011).

\section{WEB LINKS}

- CEA Registry website: A database of medical publications containing CEA that have been audited by the Center for the Evaluation of Value and Risk in Health, part of the Institute for Clinical Research and Health Policy Studies at Tufts Medical Center. All papers included are original analyses, written in English, and use QALY outcome measure(s). The website also includes a dictionary of relevant economic terms among other resources.

https://cevr.tuftsmedicalcenter.org/databases/cea-registry

- Board of Governors of the Federal Reserve System: On this website, the Federal Reserve offers exchange rates between the U.S. dollar and foreign currencies annually, monthly, and daily, recorded as far back as 1971. These data are useful 
if research analyses require converting values to or from U.S. currency for the sake of comparison between or aggregation of costs in a common monetary unit.

www.federalreserve.gov/releases/g5a/current/default.htm

- BLS: The BLS website (www.bls.gov) lists CPI, which allows comparison for the real value of money between time periods. The CPI calculator can determine conversion of the U.S. dollar's value between any years ranging from 1913 to present.

data.bls.gov/cgi-bin/cpicalc.pl

- Federal Reserve Bank of St. Louis Economic Data: This website offers extensive economic indicator data useful for economic analyses. For example, these data include the U.S. inflation rate by day, month, or year.

https://fred.stlouisfed.org

- Health Economics Resource Center (HERC): HERC is a resource for cost-effectiveness research that includes help identifying costs, definitions of economic concepts, and a bibliography of over 300 cost-effectiveness studies. This U.S. Department of Veterans Affairs website also contains actual Veterans Affairs health-economic data with registration.

www.herc.research.va.gov/include/page.asp?id=cost-effectiveness-analysis www.herc.research.va.gov/include/page.asp?id=budget-impact-analysis

\section{REFERENCES}

Agency for Healthcare Research and Quality. (2018). Medical Expenditure Panel Survey. https://meps. ahrq.gov/mepsweb

Bhandari, S. (2011). Update of a comparative analysis of cost minimization following the introduction of newly available intravenous iron therapies in hospital practice. Therapeutics and Clinical Risk Management, 7, 501-509. https://doi.org/10.2147/TCRM.S25882

Biesheuvel-Leliefeld, K. E., Kersten, S. M., van der Horst, H. E., van Schaik, A., Bockting, C. L., Bosmans, J. E., Smit, F., \& van Marwijk, H. W. (2012). Cost-effectiveness of nurse-led self-help for recurrent depression in the primary care setting: Design of a pragmatic randomised controlled trial. BMC Psychiatry, 12, 59. https://doi.org/10.1186/1471-244X-12-59

Blakely, T., Collinson, L., Kvizhinadze, G., Nair, N., Foster, R., Dennett, E., \& Sarfati, D. (2015). Cancer care coordinators in stage III colon cancer: A cost-utility analysis. BMC Health Services Research, 15, 306. https://doi.org/10.1186/s12913-015-0970-5

Brouwer, W. B., \& Koopmanschap, M. A. (2005). The friction-cost method: Replacement for nothing and leisure for free? Pharmacoeconomics, 23(2), 105-111. https://doi.org/10.2165/00019053-20052302000002

Bryant-Lukosius, D., Carter, N., Reid, K., Donald, F., Martin-Misener, R., Kilpatrick, K., Patricia Harbman, P., Kaasalainen, S., Marshall, D., Charbonneau-Smith, R., \& DiCenso, A. (2015). The clinical effectiveness and cost-effectiveness of clinical nurse specialist-led hospital to home transitional care: A systematic review. Journal of Evaluation in Clinical Practice, 21(5), 763-781. https://doi. org/10.1111/jep.12401

Campbell, J. L., Fletcher, E., Britten, N., Green, C., Holt, T. A., Lattimer, V., Richards, D. A., Richards, S. H., Salisbury, C., Calitri, R., Bowyer, V., Chaplin, K., Kandiyali, R., Murdoch, J., Roscoe, J., Anna Varley, A., Warren, F. C., \& Taylor, R. S. (2014). Telephone triage for management of same-day consultation requests in general practice (the ESTEEM trial): A cluster-randomised controlled trial and cost-consequence analysis. The Lancet, 384(9957), 1859-1868. https://doi.org/10.1016/S01406736(14)61058-8 
Centers for Medicare \& Medicaid Services. (2020, December 17). National Health Expenditure Data. CMS.Gov. https://www.cms.gov/Research-Statistics-Data-and-Systems/Statistics-Trends-andReports/NationalHealthExpendData/NationalHealthAccountsHistorical\#: :text=U.S.\%20 health\%20care\%20spending\%20grew,spending\%20accounted\%20for\%2017.7\%20percent

Cohen, C. C., Choi, Y. J., \& Stone, P. W. (2016). Costs of infection prevention practices in long-term care settings: A systematic review. Nursing Economic, 34(1), 16-24.

Determinants of health economic decisions in actual practice: The role of behavioral economics. (2006). Summary of the presentation given by Professor Daniel Kahneman at the ISPOR 10th Annual International Meeting First Plenary Session, May 16, 2005, Washington, DC, USA. Value Health, 9(2), 65-67. https://doi.org/10.1111/j.1524-4733.2006.00084.x

Drummond, M. F., Sculpher, M. J., Claxton, K., Stoddart, G. L., \& Torrance, G. W. (2015). Methods for the economic evaluation of health care programmes (4th ed.). Oxford University Press.

Eldessouki, R., \& Smith, M. D. (2012). Health care system information sharing: A step toward better health globally. Value Health Regional, 1, 118-120. https://doi.org/10.1016/j.vhri.2012.03.022

Fatoye, F., \& Haigh, C. (2016). The cost-effectiveness of semi-rigid ankle brace to facilitate return to work following first-time acute ankle sprains. Journal of Clinical Nursing, 25(9-10), 1435-1443. https:// doi.org/10.1111/jocn. 13255

Federal Coordinating Council for Comparative Effectiveness Research. (2009). Report to the President and the Congress. U.S. Department of Health and Human Services.

Garber, A. M. (2011). How the Patient-Centered Outcomes Research Institute can best influence realworld health care decision making. Health Affairs, 30(12), 2243-2251. https://doi.org/10.1377/ hlthaff.2010.0255

Gold, M. R., Siegel, J. E., Russell, L. B., \& Weinstein, M. C. (1996). Cost effectiveness in health and medicine. Oxford University Press.

Hartman, M., Martin, A. B., Benson, J., \& Catlin, A. (2019). National health care spending in 2018: Growth driven by accelerations in medicare and private insurance spending. Health Affairs, 39(1), 8-17. https://doi.org/10.1377/hlthaff.2019.01451

Hunink, M. G. M., Weinstein, M. C., Wittenberg, E., Drummond, M. F., Pliskin, J. S., Wong, J. B., \& Glasziou, P. P. (2014). Decision making in health and medicine: Integrating evidence and values (2nd ed.). Cambridge University Press.

Hunter, R. (2015). Cost-effectiveness of point-of-care C-reactive protein tests for respiratory tract infection in primary care in England. Advances in Therapy, 32(1), 69-85. https://doi.org/10.1007/ s12325-015-0180-x

Husereau, D., Drummond, M., Petrou, S., Carswell, C., Moher, D., Greenberg, D., Augustovski, F., Briggs, A. H., Mauskopf, J., \& Loder, E. (2013). Consolidated Health Economic Evaluation Reporting Standards (CHEERS) statement. The European Journal of Health Economics, 14(3), 367-372. https:// doi.org/10.1007/s10198-013-0471-6

Hutton, D. W., Krein, S. L., Saint, S., Graves, N., Kolli, A., Lynem, R., \& Mody, L. (2018). Economic Evaluation of a Catheter-Associated Urinary Tract Infection Prevention Program in Nursing Homes. Journal of the American Geriatrics Society, 66(4), 742-747. https://doi.org/10.1111/jgs.15316

Iglehart, J. K. (2009). Prioritizing comparative-effectiveness research-IOM recommendations. The New England Journal of Medicine, 361(4), 325-328. https://doi.org/10.1056/NEJMp0904133

International Society for Pharmacoeconomics and Outcomes Research. (2016). ISPOR 21st Annual International Meeting: Released Presentations. https://www.ispor.org/heor-resources/ news/view/2016/06/09/ispor-21st-annual-international-meeting-convened-key-health-carestakeholders-in-washington-dc

Jacobs, P., \& Fassbender, K. (1998). The measurement of indirect costs in the health economics evaluation literature: A review. International Journal of Technology Assessment in Health Care, 14(4), 799-808. https://doi.org/10.1017/S0266462300012095

Jacobson, G. A. (2007). CRS report for Congress: Comparative clinical effectiveness and cost-effectiveness research: Background, history and overview. (Vol. RL34208). Congressional Research Service.

Jeon, Y. H., Simpson, J. M., Li, Z., Cunich, M. M., Thomas, T. H., Chenoweth, L., \& Kendig, H. L. (2015). Cluster randomized controlled trial of an aged care specific leadership and management program to improve work environment, staff turnover, and care quality. Journal of the American Medical Directors Association, 16(7), 629.e19-629.e28. https://doi.org/10.1016/j.jamda.2015.04.005 
Kang, J., Mandsager, P., Biddle, A. K., \& Weber, D. J. (2012). Cost-effectiveness analysis of active surveillance screening for methicillin-resistant Staphylococcus aureus in an academic hospital setting. Infection Control \& Hospital Epidemiology, 33(5), 477-486. https://doi.org/10.1086/665315

Krahn, M., Guasparini, R., Sherman, M., \& Detsky, A. S. (1998). Costs and cost-effectiveness of a universal, school-based hepatitis B vaccination program. American Journal of Public Health, 88(11), 1638-1644. https://doi.org/10.2105/AJPH.88.11.1638

Krol, M., Brouwer, W., \& Rutten, F. (2013). Productivity costs in economic evaluations: Past, present, future. PharmacoEconomics, 31(7), 537-549. https://doi.org/10.1007/s40273-013-0056-3

Liljas, B. (1998). How to calculate indirect costs in economic evaluations. PharmacoEconomics, 13(1, Pt. 1), 1-7. https://doi.org/10.2165/00019053-199813010-00001

Marsden, G., Jones, K., Neilson, J., Avital, L., Collier, M., \& Stansby, G. (2015). A cost-effectiveness analysis of two different repositioning strategies for the prevention of pressure ulcers. Journal of Advanced Nursing, 71(12), 2879-2885. https://doi.org/10.1111/jan.12753

Martin-Misener, R., Harbman, P., Donald, F., Reid, K., Kilpatrick, K., Carter, N., Bryant-Lukosius, D., Kaasalainen, S., Marshall, D. A., Renee Charbonneau-Smith, R., \& DiCenso, A. (2015). Costeffectiveness of nurse practitioners in primary and specialised ambulatory care: Systematic review. BMJ Open, 5(6), e007167. https://doi.org/10.1136/bmjopen-2014-007167

McClean, S., Baerg, K., Smith-Fehr, J., \& Szafron, M. (2018). Cost savings with transcutaneous screening versus total serum bilirubin measurement for newborn jaundice in hospital and community settings: A cost-minimization analysis. CMAJ Open, 6(3), E285-E291. https://doi.org/10.9778/ cmajo.20170158

Moradi-Lakeh, M., Shakerian, S., \& Esteghamati, A. (2012). Immunization against Haemophilus Influenzae Type b in Iran; Cost-utility and cost-benefit analyses. International Journal of Preventive Medicine, 3(5), 332-340.

Neumann, P. J., Cohen, J. T., \& Weinstein, M. C. (2014). Updating cost-effectiveness-the curious resilience of the \$50,000-per-QALY threshold. The New England Journal of Medicine, 371(9), 796797. https://doi.org/10.1056/NEJMp1405158

Neumann, P. J., Sanders, G. D., Russell, L. B., Siegel, J. E., \& Ganiats, T. G. (Eds.). (2016). Cost-effectiveness in health and medicine (2nd ed.). Oxford University Press.

Patient-Centered Outcomes Research Institute. (2020, June 9). About us. http://www.pcori.org/about-us

Penz, E. D., Mishra, E. K., Davies, H. E., Manns, B. J., Miller, R. F., \& Rahman, N. M. (2014). Comparing cost of indwelling pleural catheter vs talc pleurodesis for malignant pleural effusion. Chest, 146(4), 991-1000. https://doi.org/10.1378/chest.13-2481

Riegelman, R. K. (2012). Studying a study and testing a test (6th ed.). Lippincott Williams \& Wilkins.

Ryan, P., Revill, P., Devane, D., \& Normand, C. (2013). An assessment of the cost-effectiveness of midwife-led care in the United Kingdom. Midwifery, 29(4), 368-376. https://doi.org/10.1016/j. midw.2012.02.005

Sanders, G. D., Neumann, P. J., Basu, A., Brock, D. W., Feeny, D., Krahn, M., Kuntz, K. M., Meltzer, D. O., Owens, D. K., Prosser, L. A., Salomon, J. A., Sculpher, M. J., Trikalinos, T. A., Russell, L. B., Siegel, J. E., \& Ganiats, T. G. (2016). Recommendations for conduct, methodological practices, and reporting of cost-effectiveness analyses: Second panel on cost-effectiveness in health and medicine. JAMA, 316(10), 1093-1103. https://doi.org/10.1001/jama.2016.12195

Schoonhoven, L., van Gaal, B. G., Teerenstra, S., Adang, E., van der Vleuten, C., \& van Achterberg, T. (2015). Cost-consequence analysis of "washing without water" for nursing home residents: A cluster randomized trial. International Journal of Nursing Studies, 52(1), 112-120. https://doi.org/10.1016/j. ijnurstu.2014.08.001

Skopec, L., Holahan, J., \& Elmendorf, C. (2018). Changes in Health Insurance Coverage 2013-2016: Medicaid Expansion States Lead the Way. The Urban Institute \& Robert Wood Johnson Foundation.

Stone, P. W. (1998). Methods for conducting and reporting cost-effectiveness analysis in nursing. Imagethe Journal of Nursing Scholarship, 30(3), 229-234. https://doi.org/10.1111/j.1547-5069.1998. tb01297.x

Stone, P. W. (2001a). Dollars and sense: A primer for the novice in economic analyses (Part I). Applied Nursing Research, 14(1), 54-55. https://doi.org/10.1053/apnr.2001.21025

Stone, P. W. (2001b). Dollars and sense: A primer for the novice in economic analyses (Part II). Applied Nursing Research, 14(2), 110-112. https://doi.org/10.1053/apnr.2001.22379 
Stone, P. W., Chapman, R. H., Sandberg, E. A., Liljas, B., \& Neumann, P. J. (2000). Measuring costs in cost-utility analyses: Variations in the literature. International Journal of Technology Assessment in Health Care, 16(1), 111-124. https://doi.org/10.1017/S0266462300161100

Theis, J. L., \& Finkelstein, M. J. (2014). Long-term effects of safe patient handling program on staff injuries. Rehabilitation Nursing, 39(1), 26-35. https://doi.org/10.1002/rnj.108

Twigg, D. E., Myers, H., Duffield, C., Giles, M., \& Evans, G. (2015). Is there an economic case for investing in nursing care-what does the literature tell us? Journal of Advanced Nursing, 71(5), 975-990. https:// doi.org/10.1111/jan.12577

van Baal, P. H., Polder, J. J., de Wit, G. A., Hoogenveen, R. T., Feenstra, T. L., Boshuizen, H. C., Engelfriet, P. M., \& Brouwer, W. B. (2008). Lifetime medical costs of obesity: Prevention no cure for increasing health expenditure. PLOS Medicine, 5(2), e29. https://doi.org/10.1371/journal.pmed.0050029

Van Der Biezen, M., Adang, E., Van Der Burgt, R., Wensing, M., \& Laurant, M. (2016). The impact of substituting general practitioners with nurse practitioners on resource use, production and healthcare costs during out-of-hours: A quasi-experimental study. BMC Family Practice, 17(1), 132. https://doi.org/10.1186/s12875-016-0528-6

Volpp, K. G., \& Das, A. (2009). Comparative effectiveness-thinking beyond medication A versus medication B. The New England Journal of Medicine, 361(4), 331-333. https://doi.org/10.1056/ NEJMp0903496

Wang, L. Y., Vernon-Smiley, M., Gapinski, M. A., Desisto, M., Maughan, E., \& Sheetz, A. (2014). Costbenefit study of school nursing services. JAMA Pediatrics, 168(7), 642-648. https://doi.org/10.1001/ jamapediatrics.2013.5441

Weiss, M. E., Yakusheva, O., \& Bobay, K. L. (2011). Quality and cost analysis of nurse staffing, discharge preparation, and postdischarge utilization. Health Services Research, 46(5), 1473-1494. https://doi. org/10.1111/j.1475-6773.2011.01267.x

Young, D. W. (2012). Management control in nonprofit organizations (9th ed.). Crimson Press. 